\title{
A Cross-Sectional Analysis of Food Demand in Khyber Pakhtunkhwa, Pakistan
}

\author{
Irfan Ullah*, Abbas Ullah Jan, Muhammad Fayaz, Amjad Ali and Atta Ullah Shah
}

Department of Agricultural and Applied Economics, The University of Agriculture, Peshawar, Khyber Pakbtunkbwa, Pakistan.

Abstract | This study aims to examine the food consumption decisions of households in Khyber Pakhtunkhwa Pakistan to understand the demand for different food commodities and to determine the effects of important economic factors such as prices and income. Linear Approximate Almost Ideal Demand System (LA/AIDS) model is used to estimate food demand patterns using the Household Integrated Economic Survey part of Pakistan Social and Living Standard Measurement for the year 2011-12. Fourteen food grou as per HIES including milk, meat, fruits, sugar, vegetables, beverages, wheat and wheat flour, rice, ot r cer 1 s, pulses, oil and fats, tea and coffee, backed products and other food were considered for study. $T$ da given in the survey regarding commodity prices, quantity consumed, households' food ex naityres and demographic characteristics were considered for analysis. The uncompensated pwr price elà iciny for milk, fruits, and baked products is greater than unity which suggests that the food grou are highly responsive to their own price change. Prices of these food products should he kep onstant. Imposition of any sale tax could create a huge loss in consumption for these commodities. $k, k, m_{0}$ its, other cereals, tea and coffee and baked products were treated as luxuries by the no ehold ba don the expenditure elasticities that ranged from 1.05 for milk to 1.33 for tea and con e. $W$ hi those for vegetables, pulses, rice, tea and coffee and other food ranged from 0.28 for beverag s t 9.91 for lses and considered as necessities. As the demand for milk, meat, fruits, other cereals, tea and coffee nd backed products are more elastic to total food expenditures (income). Imposition of any ind nd tax on pusonal household income could reduce their consumption of these food groups in $\mathrm{p}$ vince Sucl policies could result in food security problems for low and middle-income households i $/$ her Pakhtunkhwa Pakistan.

Received | Septen er 20,2018; Accepted | January 30, 2019; Published | March 27, 2019

*Correspondence Irfan Ullah, Department of Agricultural and Applied Economics, The University of Agriculture, Peshawar, Khyber Pakhtunkhwa, Pakistan; Email: Irfanullah@aup.edu.pk

Citation | Ullah, I., A.U. Jan, M. Fayaz, A. Ali and A.U. Shah. 2019. A cross-sectional analysis of food demand in Khyber Pakhtunkhwa, Pakistan. Sarhad Journal of Agriculture, 35(2): 378-385.

DOI | http://dx.doi.org/10.17582/journal.sja/2019/35.2.378.385

Keywords | Demand system, LA/AIDS, Food demand elasticities, Expenditures elasticities, Income elasticities

\section{Introduction}

$\mathrm{B}$ eing a developing country, Pakistan is ranked as the sixth most populous country of the world with the population growth rate of 1.92 percent. The estimated population is 191.71 million of which 116.52 million $(60.78 \%)$ in rural and 75.19 million (39.22\%) resides in urban areas (GoP, 2015). BBased on the world measures of 1.25 per adult per day, 21.04 percent of the population living below the poverty line. In the prevailing circumstances, food security concerns remain high on the policy agenda at the national level through the performance of agricultural sector has been encouraging with a growth rate of 2.1 percent during 2014-15 (GoP, 2015).

Food is essential to sustain life and to meet the human body's need and growth. The world has progressed 
through hunter-gatherer, agricultural and industrial stages to a provider of goods and services. However, many of today's world have limited access to food, causing food insecurity, particularly in the developing countries. Pakistan has attained notable improvement either from local production or imported edible product to maintain food stock, but still, food shortage is a repeated phenomenon and government is facing challenges of feeding accumulated population year by year. The mismatch between population and availability of food also affected food pattern in the country.

In Pakistan, a large fraction of total household expenditures is spent on food, and inequalities continue to persist in consumption across income groups and between urban and rural areas. The major share of expenditures (80.42\%) is incurred on food, while the overall expenditure level has gone down slightly in both rural and urban regions, i.e. $43.63 \%$ in 2013-14 from 45.01\% in 2011-12. The major chunk of consumption expenditures on food is incurred on sugar, wheat, vegetables ghee, milk and vegetables which almost share $54.75 \%$ out of $80.42 \%$. Among the food items, the poorest spend $65.63 \%$ of the total food expenditure on fruits, sugar, chicken, milk, wheat, beef, and vegetables etc which confirm differences in preferencesfor consumption expenditures (o -P,2015).

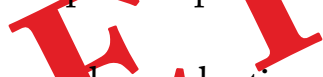

The consumption and production decisions are usually driven by government policies such as fixing production targets, imposing taxes, announcing incentives (subsidies) to promote production and sometimes intervene in the market to regulate prices. These policy implications have great influence on consumers, producers and trade alike. However, different stake holder's response differently to such decisions (Chaudhary et al., 1999). To know the effect of such interventions on food consumption decision of the population and to get insight into the challenges and opportunities associated with the agriculture sector, it is imperative to study consumer behaviour regarding food consumption.

Consumption is directly connected with the progress and development of any economy as the living standard of the individuals is measured by making the expenditures on a purchase of various consumption heads. Furthermore, as the entire setup is dependent upon the consumption pattern it provides base for the extension of business activities in the country.
Food being the primary basic need grabs the priority in the consumption of people, especially the poor classes. Since the estimates of income elasticities of food demand are required for a better design of food policy to set priorities, understanding the relationship between household consumption and income provide an insight into consumer behavior. The policy implications generated from this study will be worthy for the policy planners as well as decisionmakers of the appropriate authority in forecasting future food demand under different scenarios and framing important policy decisions for the welfare of the household in Khyber Pakhtunkhwa Pakistan. The overall average household size is 7.21, with an average income of Rs. 25186 having food consumption expenditures of Rs. 10598.50 (U1lah, 2018 ).


by asing the estimated coefficients from the Linear Approximate Almost Ideal Demand System (LA/ AIDS) model developed by Deaton and Muellbauer (1980a) and (1980b) for aggregated food groups based on the HIES 2011-12 data. The LA/AIDS provide the first order approximation to the expenditures functions and satisfies the axioms of consumer choices and allows for investigating interdependence among products (Bryne et al., 1996).

\section{Specification and estimation of the LA/AIDS}

Deaton and Muellbauer (1980a, b) derived the LA/ AIDS from a flexible expenditure function with Price Independent Generalized Logarithmic preference to derive that is extremely useful for estimating a demand system with many desirable properties. The AIDS model automatically satisfies the aggregation restriction, and with simple parametric restrictions, homogeneity and symmetry can be imposed. The LA/ AIDS system in its budget share form is given as:

$$
w_{i}=\alpha_{i}+\sum_{j} \gamma_{i j} \ln p_{j}+\beta_{i} \ln (x / p)+u_{i} \ldots . .
$$

\section{Where;}

$\alpha_{i}, \beta_{i}$ and $\gamma_{i j}$ are the parameters that need to be estimated. $W_{i}$ is the budget share of good i, $p_{j}$ is the price of good $\mathrm{j}$ and $\mathrm{x}$ is the total expenditure. $\mathrm{P}$ is the aggregate price index approximated by Laspeyres Price Index that is defined by $\operatorname{In}\left(\mathrm{P}^{\mathrm{L}}\right)=\Sigma \mathrm{W}$ In $(\mathrm{Pi}), \mathrm{n}$ is the number of goods, $\ln$ is the natural logarithm. Where, $\mathrm{Y}_{\mathrm{ij}}=1 / 2\left(\mathrm{Y}_{\mathrm{ij}}^{*}+\right.$ 
$\left.\mathrm{Y}_{\mathrm{ji}}^{*}\right)=\mathrm{Y}_{\mathrm{ij}}$ for two goods $\mathrm{i}$ and $\mathrm{j}$. Separability is imposed at the food level, implying that consumers modify their optimal food consumption bundle when relative prices of individual foods change, given an optimal allocation of expenditure on food. Due to separability, the marginal rate of substitution between any food items is independent of the changes in the nonfood items. Hence, the individual food price changes influence non-food consumption expenditures only through their influence on the allocation of total expenditures to food and non-food. The advantage of separability lies in the fact that at each stage of budgeting, information appropriate to the stage is required. To account for the household characteristics, Equation (1) is augmented with household specific socioeconomic, demographic, and regional characteristics, using the following relationship proposed by Pollak and Wales (1978; 1987):

$$
\mathrm{D}^{\mathrm{i}}(\eta)=\sum_{\mathrm{r}=1}^{\mathrm{N}} \delta_{\mathrm{ir}} \eta_{\mathrm{r}}
$$

Where;

$\eta_{\mathrm{r}}$ is a matrix of socioeconomic variables and $\delta_{\mathrm{ir}}$ is the vector of parameters. The socioeconomic variables include household size measured as the number of household members; a binary variable for the marital status of the household; and regional dummies representing the urban and rural region. Binary variables are equal to 1 when the phenomenon exists and 0 otherwise (for example, manital status equals 1 when the household is married, otherwise it is 0 ). In this study, socioeconomic, demographic, and regional characteristics included in Equation 1 as follows:

$$
w_{i}=\alpha_{i}^{* * *+}+\sum_{v} \delta_{i k} \eta_{k}+\sum_{i} \gamma_{i j} \ln \left(p_{j}\right)+\beta_{i}\left(\ln (x)-\sum_{i} \bar{w}_{j} \ln \left(p_{j}\right)\right)+\mu_{i}^{* * *} \ldots . .(3)
$$

Where;

$\alpha_{i}=\alpha_{i}^{* *}-\Sigma_{k} \delta_{i k} \eta_{k}$ The demographic and dummy variables used in the complete demand system are the same as the ones used in single equation models. Equation 3 is estimated for urban and rural regions of Pakistan. The budget shares and the price included in Equation 3 are for twelve food groups: milk, meat, fruits, vegetables, beverages, sugar, the staple food, cereals, oil and fats, tea and coffee, backed products and other food.

The theoretical restrictions i.e, adding up, homogeneity and symmetry imposed during the estimation process is as follows.

$$
\sum_{i} \alpha^{\cdots * *}=1 \text {, and } \sum_{i} \delta_{i k}=0 k=1, \ldots \ldots \ldots, m \ldots \ldots(4)
$$

To estimate the system of equation in per capita terms the seemingly unrelated regression estimation method of Zellner (1963) is employed.Using the delta method, the statistical significance of the estimated elasticities is employed. If a surveyed household does not consume a commodity, then the price for that commodity is missing; to keep these (missing) observations in the analysis, missing prices are replaced by average prices (Cox and Wohlgenant, 1986). Imposing the property of additivity of the expenditure function makes the variance and covariance matrix singular; thus, one of the equations needs to be omitted to estimate the LA-AIDS. The expenditure equation for "other food" is omitted, and the coefficients for the omitted equation are derived using the theoretical conditions imposed on the estimation process. However, the coefficients estimated using LA-AIDS are invariant to the omitted equation.



The elasticity derivations for the LA/AIDS models are widely investigated andwell documented. Following B se (1994) and Green and Alston (1991), taking the derivative of Equation 3 with respect to $\ln (x)$, the expenditure elasticity $e_{i}$ can be obtained as follows:

$$
\mathrm{e}_{\mathrm{i}}=1+\left(\frac{1}{\mathrm{w}_{\mathrm{i}}}\right)\left(\frac{\partial \mathrm{w}_{\mathrm{i}}}{\partial \ln (\mathrm{x})}\right)=1+\left(\frac{\beta_{\mathrm{i}}}{\mathrm{w}_{\mathrm{i}}}\right) \ldots .
$$

Taking the derivative with respect to $\ln (\mathrm{pj})$, uncompensated own- $(j=i)$ and cross- $(j \neq i)$ price elasticities, $e_{i j}{ }_{\text {LA/AiDS }}$, become as follows:

$\mathrm{e}_{\mathrm{ij}}^{\mathrm{LA} / \mathrm{AIDS}}=-\delta_{\mathrm{ij}}\left(\frac{\mathrm{i}}{\mathrm{w}_{\mathrm{i}}}\right)\left(\frac{\partial \mathrm{w}_{\mathrm{i}}}{\partial \mathrm{p}_{\mathrm{j}}}\right)=-\delta_{\mathrm{ij}}+\left(\frac{\gamma_{\mathrm{ij}}}{\overline{\mathrm{w}}_{\mathrm{i}}}\right)-\left(\frac{\beta_{\mathrm{i}}}{\overline{\bar{w}}_{\mathrm{i}}}\right) \overline{\mathrm{w}}_{\mathrm{j}} \forall_{\mathrm{i}} \mathrm{j}=1, \ldots \ldots, \mathrm{n} \ldots . .(6)$

\section{Where;}

$\delta_{\mathrm{ij}}$ is the Kronecker delta that is unity if $\mathrm{i}=\mathrm{j}$, and zero otherwise. The Hicksian compensated price elasticities can be derived for the LA/AIDS model. The compensated price elasticities, $\mathrm{S}_{\mathrm{ij}}{ }_{\mathrm{LA} / \mathrm{AiDS}}$, become as follows:

$s_{i j}^{\text {LA/AIDS }}=e_{i j}+e_{i} w_{j}=-\delta_{i j}+\left(\frac{\gamma_{i j}}{\bar{w}_{j}}\right)+\bar{w}_{j} \forall_{i}, j=1, \ldots \ldots, n \ldots$.

\section{Results and Discussion}

This section presents and discusses the results from the LA/AIDS model estimation for the selected food groups' budget shares. The empirical result from the Seemingly Unrelated Regression of the specified demand function shows that all estimated coefficients 
agree with a priori theoretical expectation. The parameters satisfy the adding up, homogeneity and symmetry restrictions. Overall it can also be seen from the estimated results that a reasonable number of coefficients of the explanatory variables are significant at the 99 percent level of significance.

\section{Uncompensated and compensated own/cross price and} expenditures elasticities

Uncompensated own price elasticities: The Marshallian (uncompensated) and Hecksian (compensated) own and cross-price elasticities for Khyber Pakhtunkhwa Province are given in Table 1 and Table 2. The uncompensated own price elasticity for milk (1.044), fruits (1.031), and baked products (1.025) is greater than unity which suggest that these food groups are highly responsive to own price change. The uncompensated own price elasticity of demand for the majority of the products is price inelastic ranging from 0.493 for pulses to 0.981 for rice.

Table 1: Uncompensated/compensated own price and expenditures elasticities for Khyber Pakbtunkhwa, 2011 12.

\section{Food Groups}

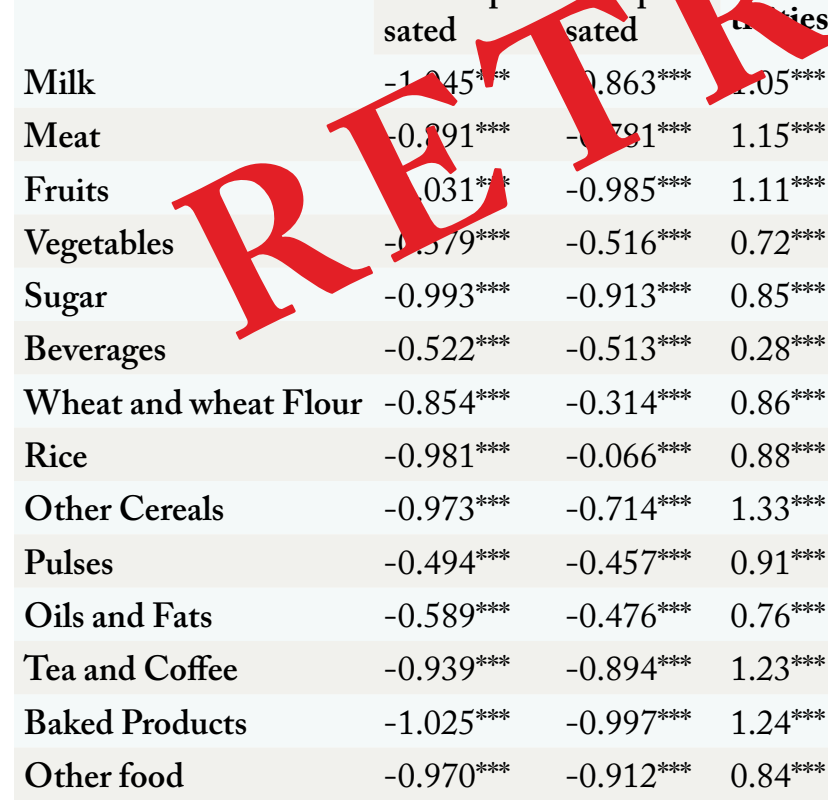

Source: Author's calculations form HIES. 2011-12.

Note: ***k indicates significant at $99 \%$; *** significant $95 \%$ and * significant at $90 \%$.

Compensated own price elasticities: The compensated own price elasticities of demand for all food groups are relatively inelastic, and its ranges vary from 0.066 (rice) to 0.996 (baked products). The compensated own price elasticities for food groups like meat (0.863), fruits (0.780), vegetables (0.516), sugar (0.913), beverages (0.513), wheat and wheat flour (0.314), rice (0.066), other cereals $(0.714)$, pulses (0.456) oils and fats (0.476), tea and coffee (0.893), baked products (0.996) and other food (0.912) were inelastic during the survey period. The estimated uncompensated own price elasticity of demand for milk, meat, fruits, vegetables, sugar, beverages, wheat and wheat flour, rice, other cereals, pulses, tea and coffee, baked products and other food indicates that if price falls by 10 percent then the demand these food groups would increase by $10.44,8.90,10.31,5.79,9.93$, $5.21,8.54,9.81,9.73,4.93,5.89,9.38,10.25$ and 9.70 percent respectively. Of this total increase in demand 8.63, 7.80, 9.84, 5.16, 9.13, 5.13, 3.14, 0.66, 7.14, 4.56, $4.76,8.93,9.96$ and 9.12 were purely due to price effect (i.e. the substitution effect) elasticity suggests. The incon ffect the price falls accounts for the remoining 1.8 (i.e, $0.44-8.63 \%=$ 1.81), 1.10, $0.46,0.63$, d , 0.87 , $1,9.15,2.58,0.36$, $1.13,0.44$ o. and 0. res ectively for milk, meat, fruis, Netab sugar, beverages, wheat and wheat fl ar, rice, other creals, pulses, tea and coffee, baked pr ucts ohd other food increase due to the increase in real income, although the absolute amount of money Income remain static. The result shows that all food groups are normal as the compensated elasticities are less than the uncompensated elasticities and are statistically significant with the expected sign. This implies that the price responsiveness of the different food groups was dependent on income, in that, real income is held constant (i.e. income is not a constant in the decision process), consumers tend to be less responsive to food prices.

The difference between the uncompensated and compensated own price elasticities of quantity demanded depends on the income effect for uncompensated demand. Smaller the difference between the own price uncompensated and compensated demand elasticities, less responsive will be the quantity demanded to change income (real) of consumers.In other words, the expenditures elasticities of quantity demanded for such food groups would be less elastic. As the demand for basic food items such as milk, fruits and baked products should be kept constant. Imposition of any sale tax could create a huge loss in consumption for these commodities. Any increase in prices of these commodities should be backed with price subsidisation policies. The findings of Moschini and Moro (1993) suggested that except 
fats and oils all goods were inelastic based on own price elasticities having similarity to our results. Paragaus et al. (2005) analysed the Malaysian meat demand by using the Linear Approximate Almost Ideal Demand System (LA/AIDS) by time series aggregate data of 1992-2002. Their own price elasticities of all meat commodities have corrected negative sign and are less than one implying inelastic price demand is in accordance with our results in term of the sign. The Marshallian cross-price elasticity estimates mostly negative which indicated gross complements among the meat products reflecting a very similar response to our consumers.

Expenditures elasticities: For Khyber Pakhtunkhwa, the expenditures elasticities of most food commodities groups are higher than unity which suggests that the majority of the households are most proven to expenditures that is incurred on the basic needs of life. For milk, meat, fruits, other cereals, tea and coffee and baked products the expenditures elasticities were; $1.05,1.15,1.11,1.33,1.23$ and 1.24 respectively suggesting that these food groups are most sensitive to income changes. It is expected that these food groups will experience an increase in demand when consumers' income increases. Vegetables (0.72), sugar (0.85), beverages $(0.28)$, wheat and wheat flour $(0.86)$, rice (0.88), pulses (0.91) and oil and fats $(0.76)$ were in range of normal goods/commodities having their expenditures elasticities between zero and one and these food items behave normally to income changes can be regarded as necessities. Expenditures elasticity obtained for different food items indicated that if the household income increased, demand for different food groups will also increase. Any policies related to tax imposition could result in food security problems and huge decrease in the expenditures on these commodities. Expenditures elasticities estimated by Moschini and Moro (1993) of meat products appeared to be somewhat higher than dairy products while in our case it is higher for milk than meat, but still consistent with their results in terms of the sign (positive). The expenditures elasticities estimated by Paragaus (2005) are similar to this study in terms of the sign but different in magnitude. Another similarity is that meat were found luxury in our study while they reported pork (1.54) and mutton (1.13) are a luxury meat product.

Uncompensated cross-price elasticities: Cross price elasticity measures the effect of a price change in one commodity on the demand of another commodity.
For Khyber Pakhtunkhwa province, uncompensated cross-price elasticities indicated that they vary in signs as shown in Table 2. The uncompensated crossprice elasticity of milk demand with respect to the prices of fruits (0.003), other cereals $(0.112)$, tea and coffee (0.030) and baked products (0.005). While the negative sign of the prices of meat $(-0.004)$, vegetables $(-0.054)$, sugar $(-0.023)$, beverages $(0.036)$, wheat and wheat flour $(-0.009)$, rice $(-0.022)$, pulses $(-0.023)$, oils and fats $(-0.068)$ and other food $(-0.007)$ with cross-price elasticity of milk demand are gross complements. Table 2 shows that the cross-price elasticity of other cereals has negative signs for all the food groups-pulses, tea and coffee, baked products and other food - indicating complementary relations with these food groups having values of $0.069,0.183$, 0.077 and 0.087 respectively. The demand for pulses have negative cross-price elasticities with oil and fats (0.022), baked products (0.004) and other food (0.006) indicating complementary relations; except tea and coffee $(0.010)$. The cross-price elasticity of pulses demand with respect to the prices of tea and coffee is having positive signs, implying substitutes. The smallest value of baked products (0.004) indicates a weak complementary relation with pulses.

Compensated cross-price elasticities: Similar to compensated own price elasticities the cross-price elasticities for Khyber Pakhtunkhwa province are statistically significant as shown in Table 2. All the compensated cross-price elasticities carry expected positive sign implying substitutes, except the crossprice elasticities of vegetables and pulses, other food and beverages, other cereals, pulses and oil and fats with wheat and wheat flour, rice with tea and coffee price, tea and coffee with other cereals and pulses with oil and fats. Wheat and wheat flour and oil and fats and vegetables, rice and beverages, tea and coffee and other cereals were found the notable complements having cross-price elasticities of $0.271,0.107,0.133$ and 0.183 respectively. While other cereals and milk and rice and fruits vegetables were found substitutes with cross-price elasticities of 0.112 and 0.145 respectively. The complementary or substitution relationship between all the remaining pairs of food groups their cross-price effects were observed very small. While the compensated crossprice elasticities were non-observable and have no importance for food policy. Table 2 shows that out of 182 uncompensated cross-price elasticities 81 are 
Table 2: Estimated own and cross-price elasticities for Khyber Pakhtunkbwa.



Uncompensated (Marshallain) Elasticities



Food

Source: Author's calculations form HIES. 2011-12.

Note: **** indicates significant at $99 \%$; * significant $95 \%$ and * significant at $90 \%$.

negative (gross complements) and 101 are positive (gross substitutes). The number of net complements equals 12 and net substitutes 170 based on the compensated cross-price elasticities. We find that most of the crossprice elasticities are significant at 99 percent level of significance.

June 2019 | Volume 35 | Issue 2 | Page 383 
This paper uses the LA-AIDS model to examine food demand pattern in Khyber Pakhtunkhwa Pakistan. In general, we obtain compensated and uncompensated own price and expenditure elasticities that are statistically significant and have the expected signs. The demand for all food is price inelastic. All of the expenditure elasticities are positive suggesting that all goods are normal with the largest expenditure elasticities found for milk, fruits, other food products. Socioeconomic and regional variables have important influences on household food demand. These findings have policy implications. For example, the highly inelastic own price elasticity of wheat and limited substitution between wheat and rice indicates the importance of wheat. An increase in the price of wheat will have a limited impact on wheat consumption and increase the total expenditure on wheat while reducing expenditures on other foods. An increase in the wheat price may be helpful for wheat growers who are net sellers of wheat but not for the largely urban net buyers of wheat who will suffer real income losses. It is therefore important to evaluate the effect of increasing wheat prices in a broader framework.

\section{Author's Contribution}

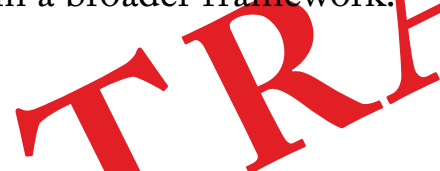

Chaudhary, M.A., E. Ahmad, A.A. Burki and M.A. Khan. 1999. Income and price elasticities of agricultural, industrial and energy products by sector and income groups for Pakistan. (unpublished research report completed by Quaidian united economic consultants for planning commission, GoP, Islamabad). Dep. Econ. Quaid-i-Azam Univ. Islamabad, Pak.

Cox, L. and K. Wohlgenant. 1986. Prices and quality effects in cross-sectional demand analysis. Am. J. Agric. Econ. 68: 908-919. https://doi. org/10.2307/1242137

Deaton, A. and L. Muellbauer. 1980a. An almost ideal demand system. Am. Econ. Rev. 70: 31226.

Deaton, A. and L. Muellbauer. 1980b. Economics and consumer behavior $C$ ambridge: Cambridge, Univ. Press, UK. ht s://do.org/10.1017/ CBO9780 11856

Food and Agriculture Organization (FAO). 2008. Food balance sheets. Food and Agriculture Organization. Available at: http://faostat.fao. org//ite/368/default.aspx (accessed August 2008).

Government of Pakistan (GoP). 2015. Household integrated economic survey. Pakistan Bureau of Statistics, Islamabad. http://www.pbs.gov.pk/ content/pakistan-social-andliving-standardsmeasurement.

Irfan Ullah: Conducted the study, reviewed literature, wrote introduction and methodology.

Abbas Ullah Jan: Developed main theme of the research, wrote abstract, conclusions and recommendations, provided technical input at every step.

Muhammad Fayaz: Provided guidance in model development.

Amjad Ali: Helped in analyzing data.

Atta Ullah Shah: Proofread the article and corrected the referecences.

\section{References}

Asian Development Bank (ADB). 2008. Food prices and inflation in developing Asia: Is poverty reduction coming to an end? Economics and research department. Spec. Rep. Asian development bank, Manila.

Buse, A.1994. Evaluating the almost ideal demand system. Am. J. Agric. Econ. 76(4): 781-793.

Byrne ,P.J., O. Capps and A. Shaha. 1996. Analysis of food-away-from-home expenditure patterns for US households, 1982-89. Am.J.Agric. Econ.
Government of Pakistan (GoP). 2007. Household integrated economic survey. Pakistan Bureau of Statistics, Islamabad.

Government of Pakistan (GoP). 2008. Pakistan economic survey 2007-08. Islamabad: Finance Div. Econ. Adviser's Wing.

Green, R. and J.M. Alston. 1991. Elasticities in AIDS Models: A clarification and extension. Am. J. Agric. Econ. 73(3): 874-875. https://doi. org/10.2307/1242842

Moschini, G. and D. Moro. 1993. A food demand system for Canada of agriculture policy branch technical report of Canada Dept. 93(1): 1-121.

Paraguas, D.S and A.A. Kamil. 2005. Analysis of meat demand in Malaysia: Model choice between Rotterdam and Aids. IRCMSA Proceeding. 237-244.

Pollack, A. and J. Wales. 1978. Estimation of complete demand systems from household budget data: The linear and quadratic expenditure systems. Am. Econ. Rev. 68: 348- 
359 .

Pollak, A. and J. Wales. 1987. Pooling international consumpti https://doi.org/10.2307/1937905 on data. Rev. Econ. Stat. 69(1): 90-99.

Ullah, I. 2018. Food consumption in Pakistan: Application of linear approximate almost ideal demand system (La/AIDS). Unpublished $\mathrm{PhD}$ Thesis.

Zellner, A. 1963. Estimators of seemingly unrelated regression: Some exact finite sample results. J. Am. Stat. Assoc. 58: 977-992. https://doi.org /10.1080/01621459.1963.10480681

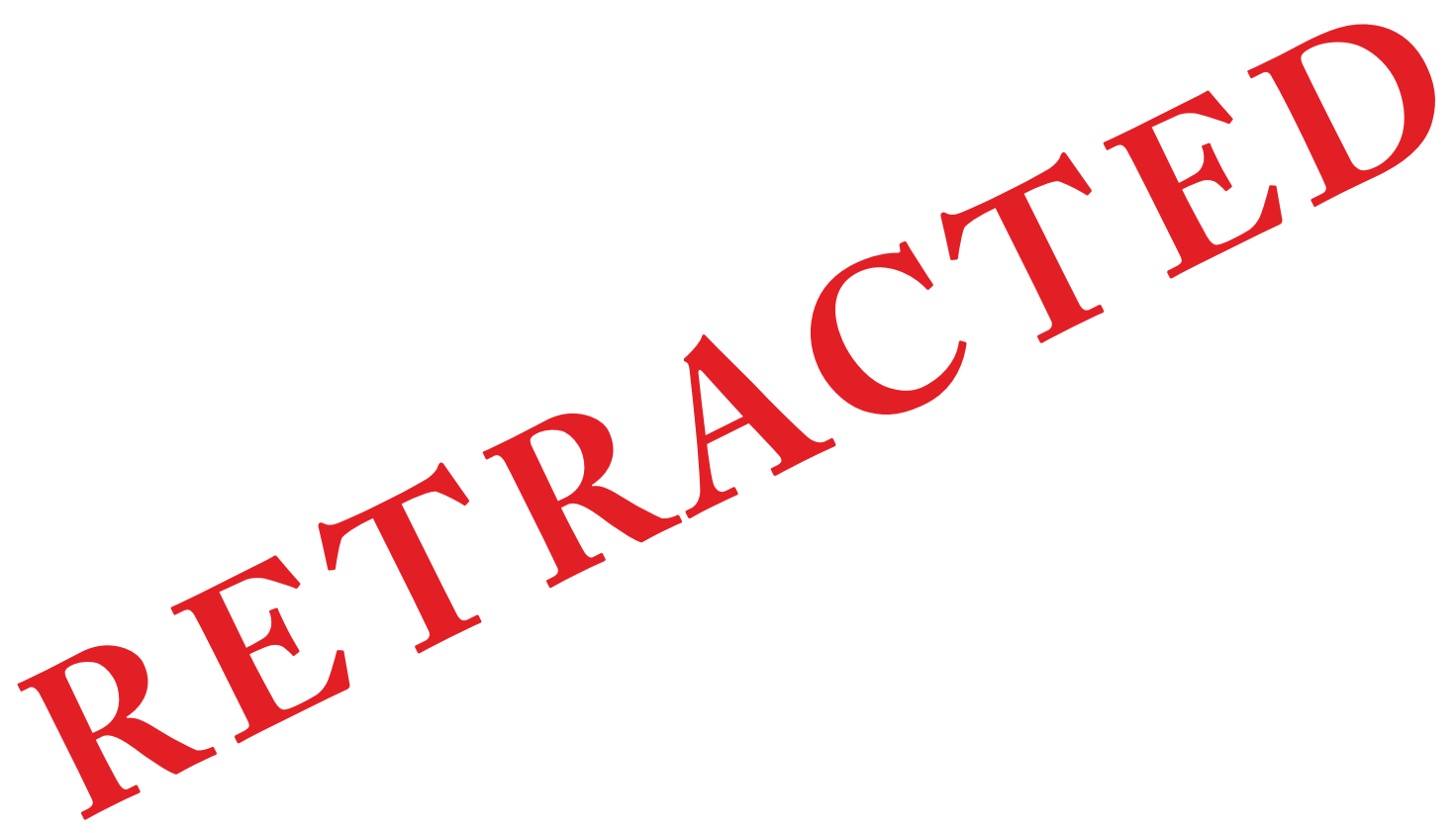

